\title{
Speech production deficits in early readers: predictors of risk
}

\author{
Judith G. Foy • Virginia A. Mann
}

Published online: 17 February 2011

(C) The Author(s) 2011. This article is published with open access at Springerlink.com

\begin{abstract}
Speech problems and reading disorders are linked, suggesting that speech problems may potentially be an early marker of later difficulty in associating graphemes with phonemes. Current norms suggest that complete mastery of the production of the consonant phonemes in English occurs in most children at around 6-7 years. Many children enter formal schooling (kindergarten) around 5 years of age with near-adult levels of speech production. Given that previous research has shown that speech production abilities and phonological awareness skills are linked in preschool children, we set out to examine whether this pattern also holds for children just beginning to learn to read, as suggested by the critical age hypothesis. In the present study, using a diverse sample, we explored whether expressive phonological skills in 92 5-year-old children at the beginning and end of kindergarten were associated with early reading skills. Speech errors were coded according to whether they were developmentally appropriate, position within the syllable, manner of production of the target sounds, and whether the error involved a substitution, omission, or addition of a speech sound. At the beginning of the school year, children with significant early reading deficits on a predictively normed test (DIBELS) made more speech errors than children who were at grade level. Most of these errors were typical of kindergarten children (e.g., substitutions involving fricatives), but reading-delayed children made more of these errors than children who entered kindergarten with grade level skills. The reading-delayed children also made more atypical errors, consistent with our previous findings about preschoolers.
\end{abstract}

\footnotetext{
J. G. Foy $(\bowtie)$

Department of Psychology, Loyola Marymount University,

1 LMU Drive, Los Angeles, CA 90045, USA

e-mail: jfoy@1mu.edu
}

\section{A. Mann}

University of California, 3151 Social Sciences Plaza, Irvine, CA 92697-5100, USA 
Children who made no speech errors at the beginning of kindergarten had superior early reading abilities, and improvements in speech errors over the course of the year were significantly correlated with year-end reading skills. The role of expressive vocabulary and working memory were also explored, and appear to account for some of these findings.

Keywords Early reading $\cdot$ Letter knowledge $\cdot$ Phonemic awareness · Speech production

\section{Introduction}

Reading impairment is now well known to be closely associated with impaired phoneme processing (Goswami \& Bryant, 1990). Children with weak phonological processing skills are highly likely to have or to develop later reading problems (Vellutino, Scanlon, Small, \& Fanuele, 2006), and children with diagnosed speech and language disorders are more likely than children without these difficulties to have later reading problems (Catts, 1993). What is less understood is how speech problems might link to reading problems.

The literature consistently links reading difficulty to speech production deficits, but what may be key is the development of strong expressive speech skills by the time the child begins to learn to read. For example, in support of their critical age hypothesis, Bishop and Adams (1990) showed that children whose speech impairments had resolved by age $5 \frac{1}{2}$ years were not at significant risk for later reading problems compared to children whose speech problems persisted by the time they entered school. This finding has been corroborated in an important series of studies further showing that preschool speech problems are more predictive of later reading problems if they persist into the early school years (Leitao \& Fletcher, 2004; Nathan, Stackhouse, Goulandris, \& Snowling, 2004a, b).

In support of the phoneme-early reading link, poor readers have difficulties with the repetition of multisyllabic words (Snowling, 1981), nonwords (Snowling, Goulandris, Bowlby, \& Howell, 1986), and phonologically complex phrases (Catts, 1986). The phonological processing deficits associated with reading problems include impaired categorization of speech sounds (Serniclaes, Van Heghe, Mousty, Carre, \& Sprenger-Charolles, 2004). For example, studies of categorization and discrimination (Tallal \& Piercy, 1974; Werker \& Tees, 1987) indicate that poor readers exhibit difficulty perceiving differences between stop consonants such as /d/ and /b/ in syllables such as /da/ and /ba/. Even 2-month old infants at familial risk for dyslexia fail to discriminate between words differing in initial stop consonants where other infants succeed (e.g., /b/ and /d/; Van Leeuwen et al., 2007). These observations about the link between speech problems and reading problems have been hypothesized to reflect phoneme representations that are fuzzy and difficult to associate with their related graphemes (e.g., Catts, Fey, Zhang, \& Tomblin, 2001; Fowler, 1991; Metsala, 1997; Swan \& Goswami, 1997; Vellutino et al., 2006).

If poor readers do have impoverished phonological representations, then it would be expected that they would show deficits not only in tasks that require them to 
assign speech sounds to phonemic categories in tests of phonemic awareness, but also in speech perception and production tasks. We are here concerned with the possibility that speech production may be linked with reading and that speech production errors, or patterns of them, might be related to reading risk. From a practical standpoint, primary language tasks such as speech production may be much easier to administer than secondary language tasks like phonemic awareness; elicited naming or repeating is far more natural for a child than comparison or manipulation of phonemes.

Phonological processing skills appear to be linked with the pattern of errors in phoneme production prior to school entry (e.g., speech errors, Keren-Portnoy, Vihman, DePaolis, Whitaker, \& Williams, 2010; Mann \& Foy, 2007; Preston \& Edwards, 2010; Rvachew \& Grawburg, 2006; Smith, 2009). Smith found that children who later developed reading problems (in second grade and beyond) had used phonologically less complex utterances in spontaneous speech at 30-months old than children with normal reading development. Recently, Keren-Portnoy and colleagues showed that speech sound production mastery in 12-24 month old children was related to stronger memory for phonological sequences. Failure to master production of the eight consonants that are typically acquired early in development also associated with deficient phonological awareness in preschoolers (Mann \& Foy, 2007), and developmentally uncommon or atypical (non-developmental) speech errors appeared to be linked with phonological awareness in preschool children (Mann \& Foy, 2007; Preston \& Edwards, 2010). The purpose of the present study was to determine whether these findings extend to children in kindergarten, which for many children is the gateway into formal reading instruction.

As a first step, we sought to explore the relationship between speech errors and early reading skills in kindergarteners, in order to explore whether certain speech sounds may be especially difficult for children having difficulty learning the alphabetic principle and developing strong letter knowledge skills. Early identification of children at risk for reading problems may allow them to receive treatment prior to experiencing reading failure. But to determine which speech errors place children at risk, it is first necessary to establish what normal development is for kindergarteners. In the largest study of its kind, about $4 \%$ of 6 -year olds in the United States were found to have developmentally inappropriate errors in speech production (Shriberg, Tomblin, \& McSweeny, 1999). Interestingly, the authors found that subgroup differences, for example, gender, ethnic/racial and socioeconomic differences, all interacted with speech errors but these differences were not examined with respect to the achievement gap well known to affect these groups. This sample also consisted of very few Hispanic children, who currently make up the largest subgroup in schools in the United States.

In the present study, we examined whether the presence, frequency, and type of speech errors is related with early reading achievement. We have previously shown that preschool children with strong speech production skills (e.g., no speech errors) have superior phonological awareness skills compared to children who do make speech errors (Mann \& Foy, 2007). Mody (2003) has proposed that children with strong phonological production skills have phonological representations that are 
more fully specified (including in articulatory detail) than children who have weaker speech production skills. This suggests that we should see delays in typical speech production development among children at risk, and atypical speech production skills may be an early indicator of a lack of distinctiveness in phonemic representations among children beginning to read. Both patterns have been observed among preschool children (Mann \& Foy, 2007; Preston \& Edwards, 2010; Rvachew \& Grawburg, 2006).

Immature speech skills have an obvious effect on phonemic awareness, but they may also penalize the learning of letter names. Letter names appear to be especially important in the early stages of learning to read (Foy \& Mann, 2006; Treiman, Sotak, \& Bowman, 2001). The current speech production norms indicate that by age 6 , children are expected to have mastered speech production of the major consonants and vowels (Shriberg et al., 1999). However, fricatives, affricates, liquids and consonant clusters may still be a problem and this has implications for the learning of letter names in American English: With the exception of W, which cannot be characterized by one phoneme type, five letter names involve fricatives $(\mathrm{C}, \mathrm{F}, \mathrm{S}, \mathrm{V}, \mathrm{Z})$, three involve affricates $(\mathrm{G}, \mathrm{H}, \mathrm{J})$, three involve liquids, and glides (L, $\mathrm{R}, \mathrm{W})$, and two involve clusters $(\mathrm{Q}, \mathrm{X})$. In short, nearly half the letter names of consonants in English involve phonemes that are later developing, and it is not unreasonable to assume that children who have not mastered the production of the major consonants in English will have a more difficult time producing letter names, and thus more difficult associating letter sounds with them.

Likewise, if children have difficulty producing speech sounds in certain syllable positions, we might expect that this difficulty might be reflected in letter name production. For example, $38 \%$ of letter names in English involve consonants in final position in words $(\mathrm{F}, \mathrm{H}, \mathrm{L}, \mathrm{M}, \mathrm{N}, \mathrm{R}, \mathrm{S}, \mathrm{X})$.

Relation between speech, vocabulary, and working memory

Accurate speech production is an aspect of expressive vocabulary, another language skill that appears to be related to reading, and may be a critical factor in how well children respond to early reading intervention (Al Otaiba \& Torgesen, 2007). In preschoolers, expressive vocabulary knowledge is highly correlated with early reading skills such as rhyme awareness, phonemic awareness, and letter knowledge (Mann \& Foy, 2003). This should come as no surprise given that letter knowledge is tied to reading ability and letter sounds and names, after all, are a set of vocabulary items that a child must master in order to understand how the alphabet works. Expressive vocabulary is predictive of response to reading intervention beginning in preschool (Hindson, Byrne, Fielding-Barnsley, Newman, \& Hine, 2005) and first grade (Berninger et al., 2002; Mathes et al., 2005). Vocabulary also relates to the effects of book-related talk during shared book-reading in preschoolers (Hindman, Connor, Jewkes, \& Morrison, 2008). Thus, expressive vocabulary, as a component of oral language skills, may be linked with early reading skills, speech production abilities, and letter knowledge. 
Another cognitive skill that appears important to reading skills development is working memory. Whereas short term memory involves capacity aspects of memory, such as reciting back a series of digits, working memory involves active manipulations of new material, such as when a child is asked to repeat a series of digits backwards, or performing several cognitive calculations simultaneously while temporarily keeping material in memory. Working memory is thought to consist of independent but interacting component processes. For example, Baddeley (1986, 2003) proposed that working memory consists of a central executive responsible for supervising and coordinating allocation of resources, a phonological loop for the processing of auditory information, a visuo-spatial scratch pad for processing visual information, and an episodic buffer linking this information chronologically.

Working memory undergoes considerable development in early childhood, in particular the executive function component (Diamond, 2005). Learning disabilities (Gathercole \& Pickering, 2001; Henry, 2001) in general, and reading disabilities specifically (Leather \& Henry, 1994; Swanson \& Jerman, 2006), may be associated with problems with the central executive component of working memory. The phonological loop component of working memory appears to drive vocabulary development until school age (Gathercole, Willis, Emslie, \& Baddeley, 1992), and has been shown to predict response to early intervention in preschool children at familial risk for reading problems (Hindson et al., 2005). Dyslexic children and their affected parents show independent deficits in both the phonological loop and in the executive function components of working memory (Berninger et al., 2006). In the present study, short-term memory (repeating digits) and working memory (reciting the digits backwards) were examined as possible associates of early reading impairment. In a separate study, we will be looking at executive function components and their relation to emergent reading skills.

The goal of the present study is to link speech error patterns to reading risk measures in kindergarten in order to provide guidance for early identification practices. Specifically, we sought to explore the following research questions:

(a) Is there a pattern of speech errors that distinguishes kindergarten children at risk for reading problems from children not at risk at the beginning of the school year?

(b) Are speech errors and reading risk also linked at year-end, after formal instruction and any intervention have proceeded?

(c) Do speech errors bear a relation to letter name errors, given the density of later-maturing phonemes in the letter names?

(d) Are speech errors linked with vocabulary and working memory abilities?

\section{Method}

\section{Participants}

Participants included 92 kindergarten children $\left(M_{\text {age }}=5.2\right.$ years, $S D=.30$, range $=4.6-5.7$ years at the beginning of the school year, 47 boys and 45 girls) 
from classes as part of a larger intervention study targeting at-risk children in four schools in the Los Angeles area that have large proportions of low income children (see Fig. 1). These schools have a history of being in the lower deciles on statesponsored testing and were sites for an intervention study that will be described in a separate study including children whose primary language was not English and/or who were fluent speakers of another language. The ethnic composition at the schools is typical of the ethnic diversity of elementary schools in the Los Angeles area: 41\% Hispanic, 32\% Black, 13\% Mixed Race, 11\% White, and 3\% Asian. Only children whose primary language was English, whose parents reported that they were not fluent speakers of another language other than English, and were not receiving special educational service, including speech therapy, through the school (i.e., did not have an active Individualized Education Plan) at the time of the study were included in the present study.

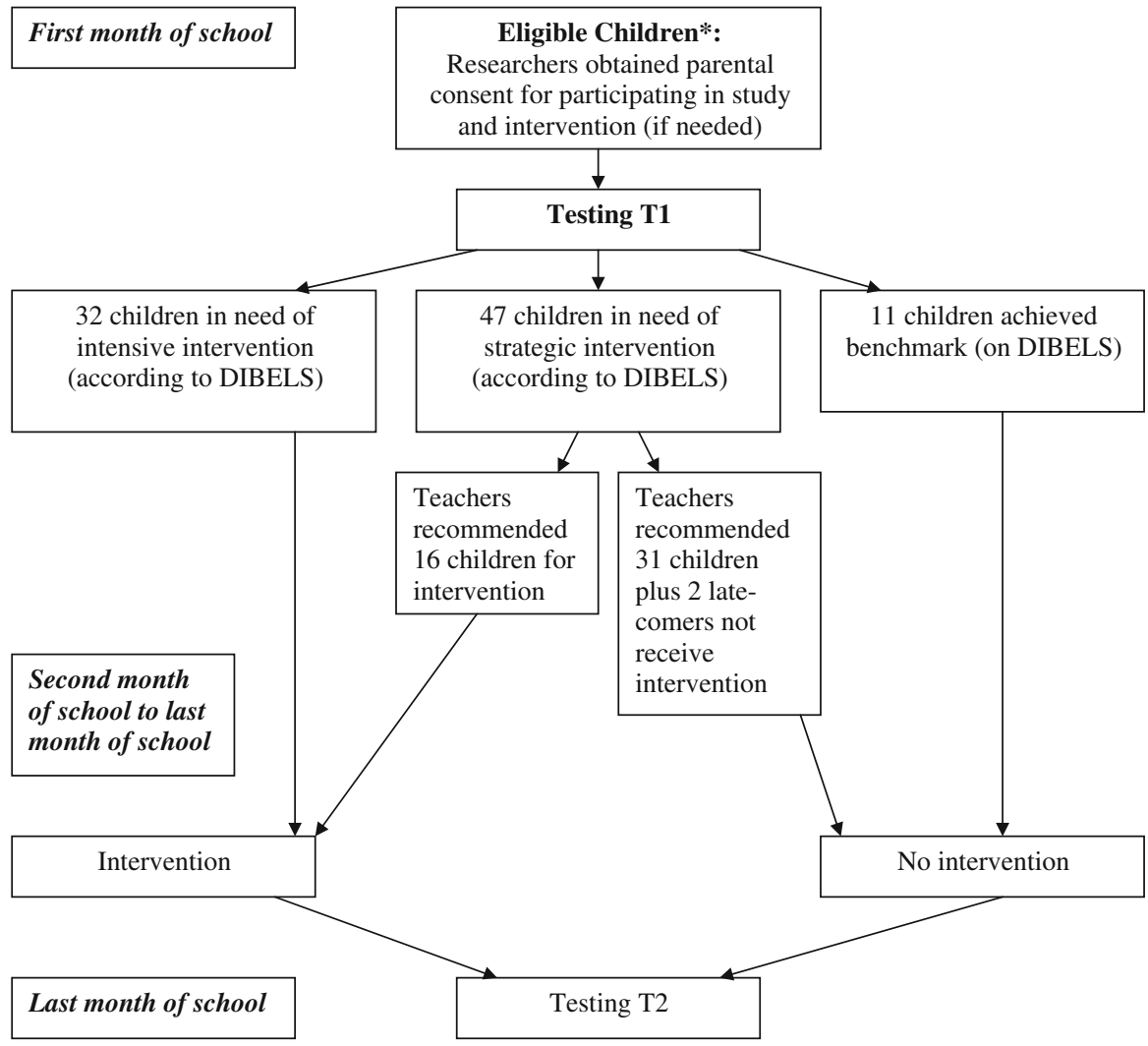

Fig. 1 Flowchart illustrating design. *Eligibility criteria: English is primary language, not fluent speakers of another language, not being considered for, or receiving special educational services (Individualized Education Plan), normal vision and hearing 
Materials

\section{Early reading skills}

The determination as to which children were at risk for later reading problems and candidates for intervention (see below) was made using The Dynamic Indicators of Basic Early Literacy Skills test (DIBELS, Compton, 2006; Kaminski \& Good, 1996). DIBELS is a set of standardized, individually administered measures that is available free to registered users. DIBELS measures that are appropriate for kindergarten assessment at the beginning of the school year are letter naming fluency (LNF) and initial sound fluency (ISF) at the first benchmark testing (within the first month of school). In the LNF task, the children are asked to name letters arranged in random sequence; the number correctly identified in 1 min yields the score. Children are not penalized for articulation errors on this task. In the ISF task, children are asked to point to one of four pictures on a series of pages that begin with a specified phoneme and for $1 / 4$ of the responses on each page, the child is asked to provide the initial phoneme for a specific picture.

DIBELS testing yields scores that correspond to labels such as low risk, some risk and at risk; or established, emerging, and deficit (University of Oregon, n.d.). Using decision rules based on the calculated odds of achieving grade level performance given current levels of performance, also available at this site, the protocol recommended by DIBELS is that each child be placed in one of three categories: (a) in need of no additional intervention (benchmark), (b) in need of strategic intervention (strategic) due to low performance on either ISF or LNF, or (c) in need of intensive intervention (intensive) due to low performance on both the ISF and LNF subtests. In the present study, 11 children achieved benchmark, 47 were in need of strategic intervention, and 32 in need of intensive intervention according to DIBELS. Children in the second categories (in need of strategic or intensive intervention services according to DIBELS) are hereafter referred to as at-risk. Details of the sample and procedures are provided in Fig. 1. Performance of each group is summarized in Tables 1 and 2 where it may be seen that the 'strategic' and 'intensive' groups are comparable to each other and different from the 'benchmark' group in cases where the 'at risk' group differs from the 'benchmark' group.

\section{Intervention}

All children in the intensive group received intervention, and the teachers helped to make final decisions about which children in the strategic group received immediate intervention and which were placed on a wait-list and monitored. In the present study, 48 children received intervention by the end of the year, none of whom left before the school year ended, and 44 children did not receive extra help beyond standard practices within the classroom upon recommendation of their teachers (see Fig. 1). Although effects of the intervention are not the focus of this paper, the results are reported in Appendices 1-3, and are consistent with previous reports of 
Table 1 Reading-related scores (means and standard error) for children who were eligible for intervention (need strategic or intensive intervention according to DIBELS) compared to children who achieved benchmark on T1 DIBELS measures

DIBELS category

Eligible for intervention

\begin{tabular}{llll}
\hline Strategic & Intensive & Total & Benchmarked \\
$n=47$ & $n=32$ & $n=76$ & $n=11$ \\
\hline
\end{tabular}

Beginning of the year

DIBELS ISF

DIBELS LNF

$5.10(.56)$

16.23 (1.69)

$.27(.09)$

$0(0)$

41.74 (1.92)

40.67 (2.79)

$30.96(2.08)$

$27.23(2.98)$

DIBELS PSF

$28.04(2.03)$

3.18 (.68)

$5.98(.59)$

$3.82(.68)$

$2.53(.39)$
$2.00(.40)$
$.38(.19)$
$0(0)$

27.77 (3.32)

5.07 (1.11)

6.07 (.86)

$3.29(.66)$

$$
\begin{gathered}
4.02(.39)^{* * *} \\
10.24(1.28)^{* * *} \\
.32(.10)^{* * *} \\
0(0)^{* * *}
\end{gathered}
$$

25.64 (2.35)

33.27 (5.18)

6.09 (1.75)

4.73 (2.11)

$$
\begin{gathered}
41.32(1.59)^{* * *} \\
29.49(1.72)^{* *} \\
27.93(1.78)^{* * *} \\
3.92(.61)^{* * *} \\
6.01(.49)^{* * *} \\
3.62(.49)^{* * *}
\end{gathered}
$$

60.18 (3.46)

40.45 (3.10)

$58.63(8.15)$

15.09 (3.42)

$13.91(2.01)$

8.91(2.00)

Children who were eligible for intervention at the beginning of the year according to DIBELS were significantly different on this measure from children who had benchmarked on DIBELS

$* p<.05 ; * * p<.01 ; * * *<.001$

significantly improving early reading skills (Foy, 2009). The intervention included children whose primary language was not English and who spoke another language fluently, although these children were excluded from the present study (see eligibility criteria for inclusion in this study in Fig. 1). Children who received the intervention participated in 1:1 tutoring three times a week for $40 \mathrm{~min}$ by trained tutors using evidence-based practices (Foy, 2009) for 20 weeks over the course of the school year. The intervention was play-based; each session involves games and fun activities that are based on letter names, letter sounds, sight word fluency, phonemic awareness, and concluded with dialogic reading of age-appropriate books.

\section{Testing}

In addition to the screening measures administered to all children whose parents provided consent, at the end of the school year following the 20 week intervention period, all children were administered the letter naming (LNF), phoneme segmenting (PSF), letter sounds (nonwords: NWF), and words read correctly (WRC) fluency subtests. At the beginning and end of the school year, the children were also asked to complete the Word Identification (real words) and Word Attack (pseudowords) subtests of Woodcock-Johnson (WJ) Reading Battery with reliability 
Table 2 Speech errors for children who were eligible for intervention (need strategic or intensive intervention according to DIBELS) compared to children who achieved benchmark on T1 DIBELS measures

\section{DIBELS category}

Eligible for intervention

\begin{tabular}{llll}
\hline Strategic & Intensive & Total & Benchmarked \\
$n=47$ & $n=32$ & $n=76$ & $n=11$
\end{tabular}

\section{Beginning of the year}

\section{Speech errors}

Total speech errors

$$
7.13(.93)
$$

$8.81(.128)$

$7.82(.76)^{*}$

$5.09(2.53)$

Age of acquisition errors

Early-8

Middle- 8

Late-8

Syllable position errors

Prevocalic

Intervocalic

Postvocalic

Manner of production errors

Nasals

Fricatives

Affricates

Liquids

Glides

Clusters

Error type

Substitutions

Omissions

Additions

Simplifications

Reading-related measures

Digits-forward

Digits-back

Expressive vocabulary

\section{End of the year}

Speech errors

Total speech errors

Age of acquisition errors

$$
\text { Early-8 }
$$

Middle- 8

Late-8

$\begin{array}{rr}.18(.07) & .31(.10) \\ 1.34(.23) & 1.16(.19) \\ 3.75(.50) & 4.41(.58)\end{array}$

$8.30(1.21)$

10.05 (1.36)

8.90 (1.17)

5.87 (.87)

2.37 (.74)

1.14 (.56)

15.91 (2.00)

4.92 (2.21)

6.06 (1.96)

1.14 (.79)

$9.63(2.21)$

$$
\begin{array}{r}
6.57(.87) \\
.25(.08) \\
.11(.05) \\
.31(.21)
\end{array}
$$

$$
4.76(.23)
$$

$1.24(.22)$

53.40 (1.63)

9.90 (1.36)

$5.51(.91)$

$2.34(.88)$

$1.74(.58)$

17.43 (2.16)

4.17 (1.50)

9.38 (2.69)

2.34 (1.31)

15.28 (3.60)

$$
\begin{gathered}
7.84(1.12) \\
.38(.13) \\
.16(.07) \\
.44(.19)
\end{gathered}
$$

4.07 (.41)

$.70(.20)$

45.07 (1.74)

$.28(.08)$
$1.26(.15)^{* *}$
$4.03(.38)^{*}$

$9.04(.91)$

$9.32(.88)^{* * *}$

$5.71(.63)$

$.25(.21)$

.73 (.63)

$2.09(.72)$

$7.11(2.95)$

4.17 (2.25)

3.03 (1.16)

$$
0 \text { (0) }
$$

$1.51(.78)$

5.94 (1.83)

$13.63(9.22)$

7.57 (6.10)

$2.27(2.27)$

10.69 (7.52)

11.97 (2.00)

3.27 (1.44)

.27 (.19)

0 (0)

1.55 (1.26)

.37 (.14)

$6.70(.34)$

$4.48(.22)^{* * *}$

$3.00(.26)$

$1.03(.16)^{* * *}$

$71.60(3.02)$

$6.77(.79)$

$7.10(.95)$

$6.90(.60)^{* *}$

$2.11(.81)$

$$
.13(.05)
$$

$.10(.06)$

$.11(.04)$

$.11(.11)$

$1.03(.25)$

$.93(.16)$

$.99(.16)$

.33 (.24)

$3.50(.37)$ 
Table 2 continued

\begin{tabular}{|c|c|c|c|c|}
\hline & \multicolumn{4}{|c|}{ DIBELS category } \\
\hline & \multicolumn{4}{|c|}{ Eligible for intervention } \\
\hline & $\begin{array}{l}\text { Strategic } \\
n=47\end{array}$ & $\begin{array}{l}\text { Intensive } \\
n=32\end{array}$ & $\begin{array}{l}\text { Total } \\
n=76\end{array}$ & $\begin{array}{l}\text { Benchmarked } \\
n=11\end{array}$ \\
\hline \multicolumn{5}{|l|}{ Syllable position errors } \\
\hline Prevocalic & $5.68(.90)$ & $7.42(1.06)$ & $6.43(.69)^{*}$ & $2.53(1.10)$ \\
\hline Intervocalic & $9.38(1.11)$ & $9.83(1.23)$ & $9.57(.82)^{* *}$ & $2.78(1.21)$ \\
\hline Postvocalic & $8.03(1.14)$ & $7.19(1.08)$ & $7.67(.79)^{* *}$ & $1.75(.88)$ \\
\hline \multicolumn{5}{|c|}{ Manner of production errors } \\
\hline Nasals & $2.19(.88)$ & $2.08(.87)$ & $2.14(.62)$ & $2.78(1.84)$ \\
\hline Stops & $.28(.19)$ & $0(0)$ & $.16(.11)$ & $0(0)$ \\
\hline Fricatives & $15.95(1.85)$ & $18.42(2.61)$ & $17.07(1.53)^{* *}$ & $3.70(2.61)$ \\
\hline Affricates & $9.58(3.52)$ & $5.00(1.42)$ & $7.62(2.11)$ & $0(0)$ \\
\hline Liquids & $5.42(2.42)$ & $7.78(2.22)$ & $6.43(1.67)$ & $0(0)$ \\
\hline Glides & $3.75(2.11)$ & $3.33(2.32)$ & $3.57(1.55)$ & $5.56(5.56)$ \\
\hline Clusters & $9.85(2.02)$ & $11.57(2.84)$ & $10.59(1.67)$ & $3.92(2.19)$ \\
\hline \multicolumn{5}{|l|}{ Error type } \\
\hline Substitutions & $5.88(.76)$ & $6.13(.81)$ & $5.99(.56)^{* *}$ & $1.78(.85)$ \\
\hline Omissions & $.20(.06)$ & $.13(.08)$ & $.17(.05)$ & $0(0)$ \\
\hline Additions & $.23(.08)$ & $.17(.07)$ & $.20(.06)$ & $.22(.15)$ \\
\hline Simplifications & $.18(.13)$ & $.40(.16)$ & $.27(.11)$ & $.11(.11)$ \\
\hline \multicolumn{5}{|l|}{ Reading-related measures } \\
\hline Digits-forward & $5.50(.32)$ & $5.27(.27)$ & $5.41(.22)$ & $7.38(.60)$ \\
\hline Digits-back & $2.07(.23)$ & $1.87(.25)$ & $1.99(.17)^{* *}$ & $4.00(.38)$ \\
\hline Expressive vocabulary & $61.70(1.77)$ & $54.38(2.99)$ & $59.18(1.60)^{* *}$ & 79.75 (2.97) \\
\hline
\end{tabular}

Children who were eligible for intervention at the beginning of the year according to DIBELS were significantly different on this measure from children who had benchmarked on DIBELS

$* p<.05 ; * * p<.01 ; * * * p<.001$

reported to range from .87 to .97 (Woodcock, 1987). The tests were administered in random order at both testing periods (T1 and $\mathrm{T} 2$ ).

\section{Speech production}

The Sounds-In-Words subtest of the Goldman-Fristoe Test of Articulation-2 (GFTA, Goldman \& Fristoe, 2000), a standardized test of articulatory skill, was administered to each child, with the responses transcribed phonetically on-line, tape-recorded, and later analyzed. The test contains 35 simple color stimulus pictures intended to elicit 44 responses. Internal reliability reported by the authors is .96 for females, and .94 for males. Test-retest reliability is .98 for initial, medial, and final sounds. Median percentages of inter-rater agreement for initial, medial, and final sounds are reported 
at 93, 90, and 90, respectively (http://ags.pearsonassessments.com/assessments/ technical/gfta.asp).

The responses elicited from the children were audiotaped and phonetically transcribed by a licensed and certified speech-language pathologist. The samples were then rechecked by the researcher or a research assistant using the audiotapes. Any differences between the transcript analyses were resolved through repeated listening to the taped response. Twenty percent of the transcripts were randomly selected for analysis by an independent research assistant blind to the research hypotheses. The percentage of agreement of the consonants transcribed for each word was calculated. The average percent of agreement for the transcripts was 97.6\% (range $95.2-100 \%$ ).

\section{Speech error analysis}

Speech errors were analyzed according to syllable position, target consonant production manner, error type, and developmental sequence.

Syllable position. On the English GFTA, 22 of the targeted phonemes are prevocalic, 20 are intervocalic, and 19 are postvocalic (Williams, 2001). Proportion of errors per syllable position was calculated by summing the errors for that position, and dividing by the number of targets for that position, and converting to a percentage.

Manner of articulation. On the GFTA, not all target phonemes are elicited with equal frequency: 8 targets are nasals, 19 are stops, 20 are fricatives, 6 are affricates, 6 are liquids, and 2 are glides, and a total of 17 clusters (modified from Williams, 2001). Errors for each manner type were calculated as a percentage of each of these totals by summing the errors for that manner type and dividing by the number of targets and converting to a percentage.

Type of Error. Each error was classified as an omission (omission of a singleton consonant), substitution (substitution of a singleton consonant), addition (addition of a consonant to a singleton consonant), or cluster simplification (omission of one phoneme from a cluster) following Porter and Hodson (2001). We also included an error category of additions (addition of a phoneme). Unlike Porter and Hodson who excluded some substitutions as errors, we scored all substitutions of phonemes as errors, including substitutions of / $/$ / and / // (lisps) for /s/ and /z/ (after Mann \& Foy, 2007).

\section{Developmental sequence}

Shriberg (1993) identified a normal developmental sequence for acquisition of consonantal phonemes based on clustering in a rank-ordered sequence of percent correct consonants in speech-delayed children. These are the Early- 8 (/p/, /b/, /j/, /n/, /w/, /d/, /m/, /h/), Middle-8 (/t/, / $\left./ /, / \mathrm{k} /, / \mathrm{g} /, / \mathrm{f} /, / \mathrm{v} /, / \mathrm{t} \int /, / \mathrm{d} z / / \mathrm{l} /\right)$, and the Late-8 (/ $\mathrm{s} /$, $/ \mathrm{s} /, / \theta /, / \delta /, / \mathrm{r} /, / \mathrm{z} /, / 3 /, / \mathrm{l} /$ ). Errors made on the Early-8 sounds (Early-8 errors), Middle-8 sounds (Middle- 8 errors), and Late- 8 sounds (Late- 8 errors) were subjected to separate analyses. Children were classified as advanced if they made no 
errors in consonant production (GFTA), typical if they made no errors on Early-8 sounds but at least one error on middle or later sounds, and delayed if they made at least one error on the Early- 8 sounds, and one or more errors on middle or late sounds (after Mann \& Foy, 2007). Most children (77.2\%) made no errors on Early-8 consonants, $38 \%$ made no Middle- 8 errors, and $13 \%$ made no Late- 8 errors. A few children $(8.9 \%)$ made no speech errors at all.

The delayed $\left(M_{\text {age }}=5.12\right.$ years, $S D=.26$, range $=4.6-5.55$ years $)$, typical $\left(M_{\text {age }}=5.19\right.$ years, $S D=.32$, range $=4.6-5.19$ years $)$, and advanced $\left(M_{\text {age }}=\right.$ 5.1 years, $S D=.21$, range $=4.81-5.49$ years) groups did not differ significantly in age. Age was not significantly correlated with any of the major variables in this study.

Working Memory. The digit span subtest of the Wechsler Intelligence Scale for Children (Wechsler, 1992) was administered to assess verbal short term and working memory. In this standardized, reliable, and valid test, the examiner says single digits at the rate of one per second, and asks the participants to repeat them forwards (Digits-F) and backwards (Digits-B). Digits-B was used as a measure of working memory, consistent with views that this is a more reliable measure of working memory than digits forward (Carroll, Snowling, Hulme, \& Stevenson, 2003; Savage, Cornish, Manly, \& Hollis, 2006). The Digits-B subtest has also been shown to be a reliable predictor of reading performance (Gathercole \& Pickering, 2001).

Expressive Vocabulary. Expressive vocabulary was measured with the Expressive Vocabulary Test-2 (EVT, Williams, 2006), an un-timed test that has high reliability and validity (Rathvon, 2004). The examiner asks the participant to label pictures and to generate synonyms for test words that are presented as a spoken word accompanied by a picture. Scores indicate the number of correct answers between basal and ceiling items.

\section{Procedure}

The children were tested individually in a quiet room at the beginning and end of the school year in two sessions lasting about 20-30 min each, as illustrated in Fig. 1.

\section{Results}

Before analysis, the data were examined for missing values, fit between their distributions and the assumptions of multivariate analysis, which were met (Tabachnick \& Fidell, 2001). To correct for the positive skewness and kurtosis in most of our measures, we used nonparametric statistics (Kruskal-Wallis and Friedman analyses, and Spearman correlations) to examine relationships between variables. These tests are appropriate statistics to use when variables have equivalent but non-normal distributions (Norusis, 2000). Regression analyses were used to examine predictive relations between speech production measures and our reading related-measures. 
Research question (a): is there a pattern of speech errors that distinguishes kindergarten children at risk for reading problems from children not at risk at the beginning of the school year?

\section{Speech error analysis}

As a first step, we describe the speech errors in our sample according to developmental sequence, syllable position, manner of speech production, and type of error in order to gain an understanding of typical versus atypical speech production performance in kindergarten-aged children.

Developmental sequence. As Fig. 2 shows, the majority of children in the sample $(71.1 \%)$ were typical in speech production, with $20 \%$ classified as delayed, and $8.9 \%$ as advanced.

A Friedman test showed that there were significant differences between errors in the developmental sequence $\left(\chi^{2}=103.60, p=.0001\right)$, with the children in the entire sample making significantly fewer errors on Early- 8 than Middle- 8 sounds $(Z=5.17$, $p=.0001)$ and Late- 8 sounds $(Z=7.56, p=.0001)$, as well as significantly fewer errors on Middle- 8 than Late-8 sounds $(Z=7.11, p=.0001)$.

Syllable position. A Friedman Test revealed significant differences between errors in the various syllable positions $\left(\chi^{2}=8.90, p=.011\right)$. Post hoc Wilcoxon signed ranks tests demonstrated, as shown in Fig. 3, that the children made significantly fewer errors on consonant productions in syllable final positions (postvocalic) than in pre-vocalic $(Z=3.66, p=.0001)$ and intervocalic positions $(Z=4.73, p=.0001)$.

Manner of articulation. A Friedman test showed that there were significant differences in errors depending on manner of articulation, $\left(\chi^{2}=175.65, p=.0001\right)$. In paired Wilcoxon ranks tests, as Fig. 4 shows, the children made significantly

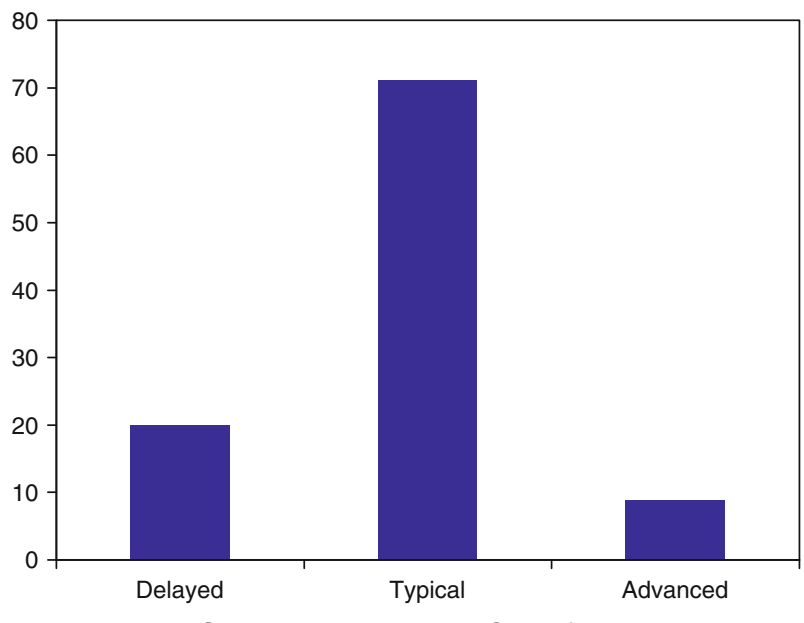

Speech Development Classification

Fig. 2 Percentage of children classified according to developmental sequence 


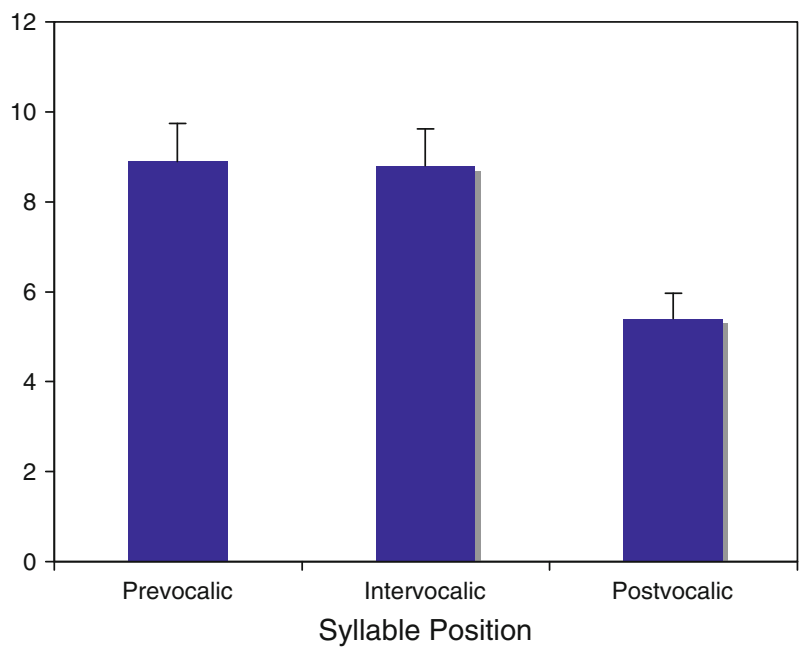

Fig. 3 Speech errors grouped by syllable position

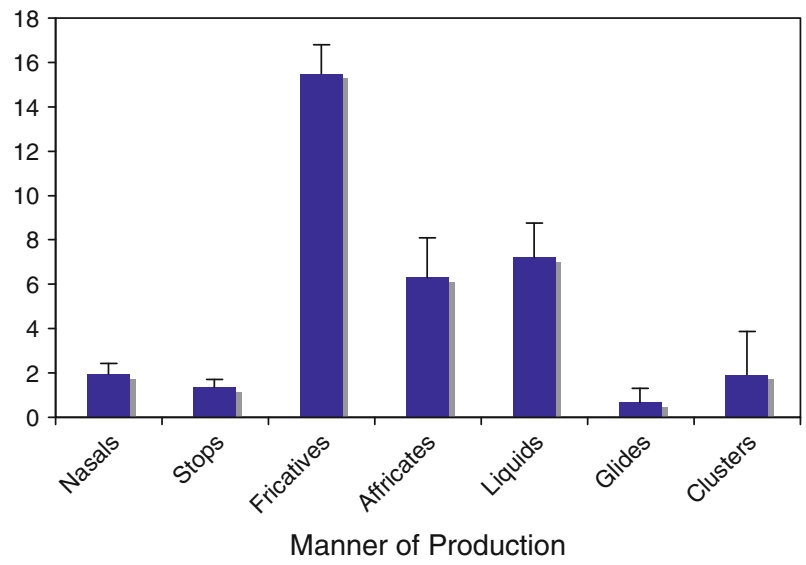

Fig. 4 Speech errors grouped by manner

more errors on fricatives than on nasals $(Z=6.79, p=.0001)$, stops $(Z=7.18$, $p=.0001)$, affricates $(Z=5.31, p=.0001)$, liquids $(Z=4.88, p=.0001)$, glides $(Z=5.91, p=.0001)$, and clusters $(Z=4.21, p=.0001)$, and more errors on clusters than on nasals $(Z=4.78, p=.0001)$, stops $(Z=5.68, p=.0001)$, affricates $(Z=3.60, p=.0001)$, liquids $(Z=3.48, p=.001)$, and glides $(Z=4.74$, $p=.0001)$. The children also made more errors on affricates than nasals $(Z=3.24$, $p=.001)$ and stops $(Z=4.05, p=.0001)$, and more errors on liquids than on stops $(Z=3.74, p=.0001)$.

Type of error. Friedman tests showed (Fig. 5) significant differences between error types $\left(\chi^{2}=190.53, p=.0001\right)$. Follow up paired Wilcoxon signed ranks tests showed than children in this study made significantly more substitution errors than 


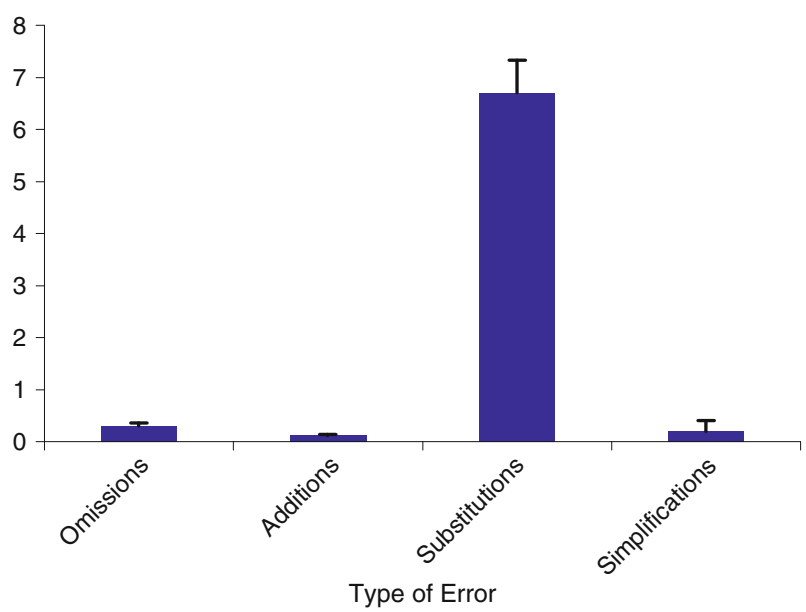

Fig. 5 Speech errors grouped by type (substitution, omission, addition, or cluster simplification)

any other type of error: omissions $(Z=7.75, p=.0001)$, additions $(Z=7.78$, $p=.0001)$, and cluster simplifications $(Z=7.73, p=.0001)$, and more cluster simplifications than omissions $(Z=2.06, p=.039)$.

Reading risk and speech production errors

In this analysis, children who were determined to be at risk (in need of strategic or intensive intervention services according to DIBELS scores at the beginning of the year) were compared to children who achieved benchmark on these early reading measures. As Table 1 shows, there were significant differences between at-risk and benchmarked children on every reading measure.

Separate Mann-Whitney $U$ tests further revealed significant differences between the groups on total numbers of speech errors $(U=247.50, p=.023)$, Middle-8 sounds $(U=222.00, p=.001)$, and Late-8 target sounds $(U=263.00, p=.046)$, intervocalic errors $(U=209.00, p=.006)$, fricatives $(U=197.00, p=.004)$, and substitutions ( $U=217.5, p=.01)$ at the beginning of the year (Table 2$)$.

Another way in which we examined risk of reading problems and speech deficits was to conduct Spearman correlations between the two DIBELS measures (ISF and LNF) and each of the speech error types for the beginning of the year measures. As Table 3 shows, at the beginning of the school year, ISF was significantly correlated with fricative errors, $r(85)=-.27, p=.014$. LNF was also significantly negatively correlated with total errors, $r(85)=-.31, p=.01$, errors on Late- 8 consonants, $r(85)=-.27, p=.013$, intervocalic consonant errors, $r(85)=-.30, p=.006$, fricative errors, $r(85)=-.24, p=.031$, clusters, $r(85)=-.22, p=.047$, and on substitutions of consonants, $r(85)=-.27, p=.013$. Scores on the WJ word reading subtest were significantly negatively correlated with Late- 8 speech errors, $r(85)=$ $-.25, p=.03$, intervocalic $r(85)=-.28, p=.01$, postvocalic speech errors, $r(85)=-.26, p=.015$, fricative errors, $r(85)=-.28, p=.01$, and substitutions 
Table 3 Spearman correlations between reading measures (initial sound fluency: ISF, letter naming fluency: LNF, Woodcock-Johnson word: WJW, and nonword reading: WJNW) and speech errors at the beginning of the year (T1) and year-end (T2)

T1 Reading measure

\begin{tabular}{llll}
\hline ISF & LNF & WJW & WJNW
\end{tabular}

T1 speech measures

Total speech errors

$-.31 * *$

$-.09$

$-.21$

Age of acquisition

Early-8

.07

.01

.10

.18

Middle- 8

$-.18$

$-.20$

$-.19$

$-.34 * *$

Late- 8

$-.17$

$-.27 *$

$-.25 *$

$-.21$

Syllable position errors

Prevocalic

$-.17$

$-.19$

$-.14$

$-.13$

Intervocalic

$-.15$

$-.30 * *$

$-.33 * *$

Postvocalic

$-.08$

$-.20$

$-.28 *$

$-.18$

Manner of production errors

Nasal

$-.17$

$-.17$

$-.14$

Stops

.09

$-.16$

.10

Fricatives

$-.27 *$

$-.24 *$

$-.25 *$

Affricates

$-.13$

$-.06$

Liquids

$-.19$

$-.14$

Glides

$-.06$

.06

Clusters

.03

$-.22 *$

$-.18$

Error type

Substitutions

$-.19$

$-.27 *$

$-.29 *$

Omissions

.05

$-.17$

$-.01$

Additions

$-.14$

$-.17$

$-.16$

Cluster simplifications

.13

$-.20$

.04

T2 speech measures

Total speech errors

Age of acquisition

Early-8

Middle- 8

Late- 8

Syllable position errors

Prevocalic

Intervocalic

Postvocalic

$-.14$

$-.26 *$

$-.17$

$-.31 * *$

$-.02$

$-.09$

$-.12$

.01

$-.10$

$-.25 *$

$-.06$

$-.19$

$-.17$

$-.25 *$

$-.14$

$-.32 * *$

$-.10$

$-.28 *$

$-.03$

$-.20$

$-.15$

$-.27 *$

$-.18$

$-.31 * *$

$-.13$

$-.23 *$

$-.15$

$-.29 *$

Manner of production errors

Nasal

.04

.02

.14

.05

.12

$-.03$

$-.09$

$-.06$

Fricatives

$-.20$

$-.26 *$

$-.18$

$-.35 * *$

$-.13$

$-.19$

$-.14$

$-.19$ 
Table 3 continued

\begin{tabular}{|c|c|c|c|c|}
\hline & \multicolumn{4}{|c|}{ T1 Reading measure } \\
\hline & ISF & LNF & WJW & WJNW \\
\hline Liquids & -.07 & $-.22 *$ & -.03 & -.17 \\
\hline Glides & .07 & -.01 & -.06 & .06 \\
\hline Clusters & -.01 & -.21 & -.16 & -.14 \\
\hline \multicolumn{5}{|l|}{ Error type } \\
\hline Substitutions & -.16 & $-.30 * *$ & -.18 & $-.32 * *$ \\
\hline Omissions & .02 & -.04 & .01 & -.14 \\
\hline Additions & -.01 & .11 & .09 & .03 \\
\hline Cluster simplifications & .01 & -.14 & .03 & -.01 \\
\hline
\end{tabular}

$r(85)=-.27, p=.013$. WJ nonword reading scores were significantly negatively correlated with errors on the Middle- 8 speech sounds, $r(85)=-.34, p=.001$, intervocalic errors, $r(85)=-.33, p=.004$, fricative errors, $r(85)=-.25, p=.03$, and substitutions, $r(85)=-.29, p=.012$. Due to the low number $(n=9)$ of children who read any nonwords, the results of this correlation involving the $\mathrm{WJ}$ scores should be interpreted with caution.

Research question (b): are speech errors and reading risk also linked at year-end?

In this analysis, we again compared children who had been at risk for reading problems at the beginning of the year (in need of strategic or intensive intervention services according to DIBELS) with children who were not at risk (had benchmarked at the beginning of the year). Mann-Whitney $U$ tests revealed $(p<.05)$ that the at-risk children still had significantly lower scores on reading measures at the end of the year (see Table 1). ${ }^{1}$ A Mann-Whitney $U$ test revealed that children who had been at risk for reading problems at the beginning of the year made significantly more speech errors at the end of the year $(U=122.00, p=.002)$, more Late- 8 errors, more prevocalic $(U=189.00, p=.044)$, intervocalic $(U=127.50, p=.003)$ and post-vocalic consonant errors $(U=141.00, p=$ $.005)$, more errors on fricatives $(U=101.00, p=.001)$, and more substitutions $(U=113.00, p=.002)$ than children who were not at-risk at the beginning of the year (see Table 2). Thus the differences between the normal and 'at risk' groups were consistent over time.

In a Spearman correlation, early reading scores at the end of the school year were significantly correlated with year-end speech errors (Table 4). T2 LNF was inversely correlated with year-end (T2) speech errors, $r(84)=-.22, p=.041$, Late-8 errors,

\footnotetext{
${ }^{1}$ The at-risk group includes children who received the intervention and those who did not receive additional help beyond standard classroom practices. Effects of the intervention are summarized in Appendices 1-3.
} 
Table 4 Spearman correlations between reading measures (letter naming fluency: LNF, phoneme segmenting fluency: PSF, nonword fluency: NWF, words read correctly: WRC, Woodcock-Johnson word: WJW, and nonword reading: WJNW) and speech errors at the end of the year (T2)

\begin{tabular}{|c|c|c|c|c|c|c|}
\hline & \multicolumn{6}{|c|}{$\mathrm{T} 2$ reading measure } \\
\hline & LNF & PSF & NWF & WRC & WJW & WJNW \\
\hline \multicolumn{7}{|l|}{ T1 speech measures } \\
\hline Total speech errors & -.21 & -.03 & -.10 & -.05 & -.11 & -.15 \\
\hline \multicolumn{7}{|l|}{ Age of acquisition } \\
\hline Early-8 & -.09 & .17 & -.08 & .12 & .00 & -.13 \\
\hline Middle-8 & -.21 & -.09 & -.05 & -.14 & -.13 & -.14 \\
\hline Late- 8 & -.12 & -.01 & -.06 & -.04 & -.09 & -.10 \\
\hline \multicolumn{7}{|l|}{ Syllable position errors } \\
\hline Prevocalic & -.08 & .03 & .10 & -.03 & -.11 & -.09 \\
\hline Intervocalic & -.20 & -.06 & -.06 & -.04 & -.11 & -.10 \\
\hline Postvocalic & -.17 & .00 & -.07 & -.04 & -.11 & -.17 \\
\hline \multicolumn{7}{|c|}{ Manner of production errors } \\
\hline Nasals & -.14 & .01 & .04 & -.10 & -.06 & -.05 \\
\hline Stops & -.17 & -.02 & .00 & .07 & -.16 & -.14 \\
\hline Fricatives & -.19 & -.07 & -.07 & -.08 & -.11 & -.12 \\
\hline Affricates & -.06 & .16 & -.10 & .05 & .07 & .11 \\
\hline Liquids & -.02 & -.08 & -.06 & -.10 & -.02 & -.08 \\
\hline Glides & -.09 & .10 & .00 & .05 & -.06 & -.09 \\
\hline Clusters & -.20 & -.04 & -.10 & -.02 & -.05 & -.12 \\
\hline \multicolumn{7}{|l|}{ Error type } \\
\hline Substitutions & -.17 & -.04 & -.07 & -.07 & -.10 & -.11 \\
\hline Omissions & -.18 & -.03 & -.15 & .06 & -.15 & $-.22 *$ \\
\hline Additions & -.13 & -.05 & .00 & -.04 & -.02 & -.08 \\
\hline Cluster simplifications & -.19 & .02 & -.14 & -.09 & -.03 & -.14 \\
\hline \multicolumn{7}{|l|}{ T2 speech measures } \\
\hline Total speech errors & $-.22 *$ & -.11 & -.14 & -.15 & -.13 & -.19 \\
\hline \multicolumn{7}{|l|}{ Age of acquisition } \\
\hline Early-8 & -.01 & .12 & .10 & .13 & -.10 & -.07 \\
\hline Middle-8 & -.09 & .10 & -.07 & -.10 & -.16 & $-.24 *$ \\
\hline Late- 8 & $-.24 *$ & -.19 & -.15 & -.21 & -.13 & -.16 \\
\hline \multicolumn{7}{|l|}{ Syllable position errors } \\
\hline Prevocalic & -.20 & -.04 & -.13 & -.02 & -.16 & -.11 \\
\hline Intervocalic & $-.22 *$ & -.14 & -.15 & -.15 & -.17 & $-.24 *$ \\
\hline Postvocalic & $-.26^{*}$ & -.14 & -.17 & $-.27 *$ & -.16 & $-.24 *$ \\
\hline \multicolumn{7}{|c|}{ Manner of production errors } \\
\hline Nasals & .05 & .07 & -.04 & -.19 & -.08 & -.08 \\
\hline Stops & -.02 & -.01 & -.10 & .02 & -.13 & $-.22 *$ \\
\hline Fricatives & $-.27 *$ & -.20 & -.18 & -.14 & -.18 & $-.22 *$ \\
\hline Affricates & -.13 & .06 & -.10 & -.03 & -.02 & -.11 \\
\hline
\end{tabular}


Table 4 continued

\begin{tabular}{lcccccc}
\hline & \multicolumn{7}{l}{ T2 reading measure } & & & \\
\cline { 2 - 7 } & LNF & PSF & NWF & WRC & WJW & WJNW \\
\hline Liquids & -.07 & -.02 & -.08 & .07 & -.06 & -.11 \\
Glides & .04 & .14 & .13 & .07 & -.02 & .10 \\
Clusters & -.11 & -.01 & -.08 & .03 & .05 & -.01 \\
Error type & & & & & & \\
Substitutions & $-.22^{*}$ & -.04 & -.12 & -.14 & -.18 & -.15 \\
Omissions & -.13 & $-.24^{*}$ & -.19 & -.01 & -.18 & $-.23^{*}$ \\
Additions & -.01 & -.05 & -.08 & -.18 & -.14 & -.18 \\
Cluster simplifications & -.17 & -.04 & -.19 & -.06 & -.01 & -.05 \\
\hline
\end{tabular}

$* p<.05 ; * * p<.01 ; * * * p<.001$

$r(81)=-.24, p=.033$, intervocalic errors, $r(81)=-.22, p=.05$, postvocalic errors, $r(81)=-.26, p=.02$, fricative errors, $r(81)=-.27, p=.017$, and substitutions $r(80)=-.22, p=.05$. WJ nonwords were significantly correlated in Spearman analyses with Middle- 8 errors $r(82)=-.24, p=.034$, intervocalic $r(82)=-.24$, $p=.034$ and postvocalic errors, $r(82)=-.24, p=.03$, errors on stops $r(82)=-.22$, $p=.05$, and fricatives, $r(85)=-.22, p=.05$, and omissions $r(85)=-.23, p=.041$.

Predictive relations between reading scores and speech errors

Do $T 1$ reading measures predict $T 2$ speech measures? In a Spearman correlation, early reading scores at the beginning of the school year were significantly correlated with year-end speech errors (Table 3). Specifically, T1 LNF was inversely correlated with year end (T2) speech errors, $r(82)=-.26, p=.019$, Middle-8 errors, $r(79)=-.25, p=.025$, Late- 8 errors, $r(79)=-.25, p=.03$, prevocalic errors, $r(79)=-.28, p=.012$, intervocalic errors, $r(79)=-.27, p=.016$, and postvocalic errors, $r(79)=-.23, p=.042$, fricative errors, $r(79)=-.26, p=.021$, liquid errors, $r(79)=-.22, p=.049$, and substitutions, $r(79)=-.30, p=.008$. WJ nonwords at T1 were significantly correlated with year-end speech errors, $r(79)=-.31, p=.005$, Late-8 errors, $r(79)=-.32, p=.005$, intervocalic, $r(79)=-.31, p=.006$, and postvocalic errors, $r(79)=-.29, p=.011$, and fricative errors, $r(79)=-.35, p=.002$, and substitutions, $\mathrm{r}(79)=-.32, p=.005$.

Do $T 1$ speech measures predict $T 2$ reading? As shown in Table 4, omissions at the beginning of the year were significantly linked in Spearman correlations with year-end WJ nonwords, $r(79)=-.22, p=.049$.

Speech error improvements and reading. Improvements in speech errors were calculated as difference scores for each of the speech error scores. Improvements in the Late- 8 speech sounds for all children in the sample were significantly correlated with year-end scores in PSF, $r(79)=.29, p=.011$ and improvements in fricatives were significantly with year-end scores in PSF, $r(79)=.25, p=.029$, and NWF, $r(79)=.26, p=.023$. 
Research question (c): do speech errors bear a relation to letter naming errors, given the density of later-maturing phonemes in the letter names?

As shown in Tables 3 and 4, letter naming fluency was significantly correlated with Late- 8 errors $r(85)=-.27, p=.013$, as well as errors on fricatives at the beginning, $r(85)=-.24, p=.031$, and end of the year, $r(79)=-.26, p=.021$.

Research question (d): are speech errors linked with vocabulary and working memory abilities?

In this analysis, we sought to explore the role of vocabulary and working memory in expressive phonological processing. We conducted three sets of analyses: Beginning of the year (T1) EVT and memory with T1 reading scores, and end of the year (T2) EVT and memory with T2 reading scores, as well as T1 EVT and memory with $\mathrm{T} 2$ reading scores.

As a preliminary step we showed, using Wilcoxon signed ranks tests, significant improvements in the entire sample from the beginning of the year for Digits-F $(Z=4.12, p=.0001)$, Digits-B $(Z=5.37, p=.0001)$, and EVT $(Z=6.212$, $p=.0001)$. Mann-Whitney $U$ tests showed that children at risk for reading problems according to DIBELS (see Table 2) had significantly lower Digits-F $(U=106.5, p=.0001)$, Digits-B $(U=100.5, p=0001)$, and EVT, $(U=59$, $p=.0001)$ at the beginning of the year and lower scores on EVT at the end of the year $(U=33, p=.0001)$ than children who were not at risk. Wilcoxon signed ranks tests showed that there were significant improvements in Digits-F $(U=4.12$, $p=.0001)$, Digits-B $(U=5.36, p=.0001)$, and EVT $(U=6.212, p=.0001)$ from $\mathrm{T} 1$ to $\mathrm{T} 2$.

As shown in Table 5, at the beginning of the school year, Digits-F, Digits-B and EVT were significantly correlated with all reading measures (ISF, LNF, WJ words,

Table 5 Spearman correlations between memory (digits-forward: DF and digits back: DB) and expressive vocabulary (EVT) and reading scores at the beginning (T1) and end of the year (T2)

\begin{tabular}{|c|c|c|c|c|c|c|}
\hline & \multicolumn{3}{|l|}{$\mathrm{T} 1$} & \multicolumn{3}{|l|}{$\mathrm{T} 2$} \\
\hline & DF & DB & EVT & DF & DB & EVT \\
\hline ISF & $.22 *$ & $.42 * * *$ & $.36 * *$ & - & - & - \\
\hline LNF & $.45 * * *$ & $.43 * * *$ & $.49 * * *$ & $.29 * *$ & $.33 * *$ & $.44 * * *$ \\
\hline PSF & - & - & - & $.26^{*}$ & .14 & $.40 * *$ \\
\hline NWF & - & - & - & $.29 * *$ & $.25^{*}$ & $.36 * *$ \\
\hline WRC & - & - & - & .15 & .12 & $.30 *$ \\
\hline WJ words & .20 & $.36^{* * *}$ & $.36^{* *}$ & $.27 * *$ & $.37 * *$ & $.47 * * *$ \\
\hline WJ nonwords & $.41 * * *$ & $.44 * *$ & $.47 * * *$ & .20 & $.31 * *$ & $.46 * * *$ \\
\hline
\end{tabular}

$* p<.05 ; * * p<.01 ; * * * p<.001$ 
and WJ nonwords), except that the correlation between Digits-F and word reading did not achieve statistical significance, $p<.05$. At the end of the year, Digits-F, Digits-B, and EVT were significantly correlated with most of the reading measures (LNF, PSF, NWF, WRC, WJ Words, WJ Nonwords). Digits-F, however, was not significantly correlated with WRC or WJ nonwords nor was Digits-Back significantly related with PSF or WRC at the end of the year.

Beginning of the year: contributions of memory and vocabulary to speechreading links

To further explore whether the links between speech and reading skills at the beginning of the school year were associated with vocabulary and memory, we conducted a series of hierarchical regression analyses. Fricative errors, the most common type of error, did not account for additional variance in Initial Sound Fluency (ISF) when EVT and memory (Digits-F and Digits-B) were partialed out. EVT $(\beta=.42, p=.0001)$ and Digits-B $(\beta=.23, p=.037)$ were significantly associated with ISF, $R^{2}=.40, p=.0001$.

When the effects of EVT and memory were partialed out, none of the Letter Naming Fluency correlates (Late-8 errors, intervocalic consonant errors, fricatives, substitutions,) were significantly associated with LNF except for clusters, which were significantly independently associated with LNF scores $(\beta=-.21, p=.019)$, $R^{2} \Delta=.044, p=19$. EVT $(\beta=.36, p=.002)$ and Digits-B $(\beta=.26, p=.018)$ were significantly associated with LNF, $R^{2}=.39, p=.0001$.

Likewise, Middle- 8 errors were not significantly linked with WJ nonword scores when the effects of EVT and memory were partialed out. EVT $(\beta=.43, p=.047)$ was significantly associated with LNF, $R^{2}=.30, p=.005$.

Year end: contributions of memory and vocabulary to speech-reading links

To further explore whether the links between speech and reading skills at the end of the school year were associated with vocabulary and memory, we conducted a series of hierarchical regression analyses on all the associations that were significant in the first-order correlation analyses. Hierarchical regression first entering digits forward and digits back and expressive vocabulary, showed that only Late- 8 speech errors $(\beta=-.24, p=.048), R^{2} \Delta=.05, p=.05$, and postvocalic errors $(\beta=-.28, p=$ $.022), R^{2} \Delta=.07, p=.022$, were independently related to LNF.

$T 1$ and $T 2$ relations between reading measures and speech errors. Hierarchical regressions partialing out the effects of $\mathrm{T} 1$ memory and vocabulary on relations in Tables 3 and 4 that were statistically significant in zero-order Spearman correlations revealed that T1 LNF was independently related to T2 total speech errors $(\beta=-.28$, $p=.05), R^{2} \Delta=.05, p=.05$, errors on clusters $(\beta=-.36, p=.02), R^{2} \Delta=.07$, $p=.02$, and substitutions $(\beta=-.30, p=.05), R^{2} \Delta=.05, p=.05$. T1 speech errors did not significantly predict any $\mathrm{T} 2$ reading measures. 


\section{Discussion}

Typical speech production errors for kindergarteners

In order to study the relation between speech errors and early reading skills, we first sought to describe speech production patterns in our kindergarten sample. Our results showed that, despite our focus on children in low-SES areas attending schools with a history of low achievement, it was quite common for kindergartens in our sample to make few speech errors. Indeed, $15.2 \%$ of the children in the sample made fewer than two speech errors on the target words during assessment. When kindergartners did make speech errors at the beginning of kindergarten, they occurred more frequently on Late- 8 sounds than sounds that typically develop earlier, were more likely for consonants in initial and medial positions than final (Fig. 3), and more common on fricatives and clusters than speech sounds involving other manners of production (Fig. 4). Speech errors in our kindergarten sample typically involved substitutions; omissions, additions, and cluster simplifications occurred infrequently. We explore below the possible reasons for these error patterns being relatively common in the speech of kindergarteners.

Developmental sequence. Kindergarteners made relatively fewer errors on the Early-8 consonants, which include nasals $(/ \mathrm{n} /, / \mathrm{m} /)$ glides, and stops. Shriberg \& Kwiatkowski (1994) have argued that mastery of these Early-8 sounds should occur by 3 years. We found that errors on Early- 8 sounds were pertinent in preschoolers (Mann \& Foy, 2007) but not kindergarteners, suggesting that the Early-8 problems reported in this prior study were a manifestation of delay and not atypical development.

Syllable position. At the beginning of kindergarten, the children in this sample made relatively fewer errors on final sounds than other sounds. This is not a finding typical of younger children, and may reflect the fact that our kindergarten children are at an age where they are mastering fricatives, which tend to be mastered in final position before initial position. At the end of the school year, they made more speech errors on intervocalic (medial) consonants compared to sounds in other positions. There is some evidence that medial phonemes are harder and later developing than at least initial sounds. As for the persistence of medial errors relative to initial and final, spelling errors are more common in medial and final position (Stage \& Wagner, 1992) and spelling of initial phonemes is more accurate than in either medial and final position (Treiman, Berch, \& Weatherston, 1993). Anthony and Francis (2005) also report that phonemic awareness is acquired for initial and final word positions before medial.

Speech sound type. Kindergarteners in our sample made more speech errors on fricatives (which make up $75 \%$ of the Late- 8 sounds) and clusters than other speech sound types. Arguably, fricatives and clusters are motorically more difficult compared to the other sounds (Kent \& Read, 1992), and our findings add to the body of literature showing the relatively late mastery of fricatives in children who are primary speakers of English (Mann \& Foy, 2007; Shriberg \& Kwiatkowski, 1994; Shriberg, Kwiatkowski, \& Gruber, 1994; Smit, 1993a, b). Although fricatives are easier to sustain than stops, they are relatively less sonorous than nasals, liquids, and 
glides (Treiman, 1984); and Treiman and her colleagues have shown greater performance deficits for phonological awareness tasks involving fricatives than for tasks involving stops (see Treiman, Broderick, Tincoff, \& Rodriguez, 1998).

Error Type. Most kindergartners' speech errors involved substitutions, rather than omissions or additions when they did make speech errors. All of the additions in this study involved the addition of $/ \mathrm{k} /$ or $/ \mathrm{g} /$ to $/ \mathrm{g} /$ in the word ring. Almost all were limited to one classroom, and additions in this classroom increased by the end of the year, apparently being influenced by the African American Vernacular English (AAVE) style the teacher was using.

Speech errors and early reading risk

Consistent with the critical age hypothesis (Bishop \& Adams, 1990) and its modified version (Nathan et al., 2004b), we found that children who made no speech errors tended to have superior early reading skills compared to those who made frequent speech errors. Children who entered kindergarten at risk for later reading problems made speech errors that were developmentally normal, but more frequent than children with typical early reading development. For example, they had higher rates of intervocalic (medial) consonant errors, errors on fricatives and clusters, substitutions, and errors on Late- 8 consonants than children who were at grade-level upon school entry. Improvement in speech skills was also linked with stronger reading skills at the end of the year (whether spontaneous or due to intervention), suggesting that children's speech error patterns may be early indicators of difficulty learning to read.

Our findings add to a growing body of evidence showing a link between speech sound production and the strength of phonological representations. Specifically, we found that children with the strongest early reading skills at year-end had improved the most in production accuracy of the Late- 8 sounds (which include a high proportion of fricatives) and specifically of fricatives. Although none of the studies conducted to date (Keren-Portnoy et al., 2010; Mann \& Foy, 2007; Smith, 2009), including our own, can provide causal conclusions, collectively they do suggest that perhaps language use, and, in this case, experience with certain kinds of speech sound productions, may be associated with robust representations of phonemes associated with early reading development. Although speech production skills most likely reflect qualitative aspects of phoneme representations, our findings, combined with that of other researchers, raise the possibility of great importance to early reading interventionists, that at least a bidirectional relationship might exist between expressive speech production experiences and the development of robust receptive phoneme representations. Such representations would arguably permit easy mapping of phonemes onto orthographic representations, as is required for children to learn to read.

Both of the DIBELS tests that were administered to kindergarteners bore a relationship to speech production errors. Letter Naming Fluency was significantly correlated with errors on fricatives at the beginning and end of the year, but not the other singleton phonemes, suggesting that the fricative speech errors may make it 
harder to name letters fast, as in a timed test such as DIBELS, especially given that fricatives are involved in proportionally more letter names than other speech sounds. Unfortunately, the DIBELS LNF task, which was used as the measure of letter knowledge in the present study, does not randomly assess all letters, and the time limit $(1 \mathrm{~min})$ for the task results in some children completing more letter productions than others. The test also includes repetition of some letters. These characteristics of the letter naming task make an analysis of the direct relationship between speech production of specific sounds and their associated letter names impossible. Future research, assessing all letter names, may indicate whether the speech errors were related to letters that contained those speech sounds. At-risk early readers also made more non-developmental errors than children with typical early reading skills including higher rates of errors on nasals, additions and omissions, and these are less directly linked to the speech sounds within letter names.

Phonemic awareness was also related to speech errors, especially to fricatives and clusters. In the phonemic awareness task we used (ISF), however, children are only required to articulate the word including the target sound for a quarter of the items. In the remainder of the items, the children point to a picture. The relationship between performance on articulation and sound fluency is thus more abstract, and might be accounted for by a common reliance on the strength of phonological representation hypothesized to be a factor in reading readiness (Fowler, 1991; Fowler \& Swainson, 2004; Walley, 1993; Walley, Metsala, \& Garlock, 2003).

All of these findings suggest that children entering kindergarten with speech problems may be strong candidates for early reading intervention by virtue of underlying phoneme processing problems linked to difficulties learning letter names and their associated sounds. Efforts that result in improved speech skills may also link with improvements in early reading skills. In particular, numerous speech errors and non-developmental patterns may be markers of special risk in kindergarteners.

Vocabulary and working memory correlates of speech production errors

We found considerable evidence for the link between vocabulary, working memory, and reading proficiency that had been previously reported in the literature (Gathercole, Alloway, Willis, \& Adams, 2006; Gathercole \& Baddeley, 1993). Expressive vocabulary and memory were linked with all of our early reading measures at the beginning and most of the reading measures at the end of the year. Children with low scores on phonological awareness and letter knowledge fluency measures (according to DIBELS) at the beginning of kindergarten had impaired vocabulary and memory (short-term and working) compared to children who had grade-level skills upon kindergarten entry.

Given their strong associations with early reading, we expected that at least some of the variance between speech production skills and early reading would be explained by expressive vocabulary and memory. Indeed, most of the relations were no longer significant when these effects were partialed out. Relationships that 
appeared to be independent of the effects of expressive vocabulary and memory were the link between errors on clusters of consonants (occur in two letter names: Q and X) and letter naming fluency at the beginning of the year, and the link between Late- 8 and post-vocalic errors and letter naming fluency at the end of the year. Given that about $40 \%$ of letter names in the English alphabet involve Late- 8 developing consonants and $38 \%$ involve postvocalic consonantal speech sounds (F, H, L, M, N, R, S, X), these findings suggest that speech errors that are considered to be developmentally appropriate for kindergarteners may nonetheless be associated with difficulty learning letters during kindergarten. Phonemic awareness and speech production skills appeared to share variance with expressive vocabulary and memory abilities, although all of these measures showed improvements over the course of the year. A further implication of our study, consistent with a growing body of evidence linking working memory to reading skill (e.g., Savage, Lavers, \& Pillay, 2007), is that efforts to improve vocabulary and working memory in children entering kindergarten may be especially effective in maximizing children's achievement of early reading skills. Whereas changes in working memory are clearly affected by age (e.g., Gilchrist, Cowan, \& Naveh-Benjamin, 2009), aspects of working memory may be modifiable by experience (Dahlin, Neely, Larsson, Backman, \& Nyberg, 2008; but see Engel, Sanos, \& Gathercole, 2008; Klingberg et al., 2005) and thus by intervention and classroom experiences. Our findings suggest that individual differences in vocabulary and memory play a major and perhaps reciprocal role in the development of early reading and expressive phonological skills.

Limitations of our study suggest that future research is warranted. Our sample tended to consist of children with very low early reading skills upon kindergarten entry: We might expect a different patterns of results in children with stronger letter knowledge, phonemic awareness, and oral language skills as presumably these children would have more robust phonological representations, and may show different patterns of speech production errors linked to later literacy skills. The fact that only 11 children achieved benchmark may limit our ability to generalize, as does the fact that some of the 'at risk' children did not receive interventions. Yet we are encouraged by the fact that, despite such noise in our subject pool, we did observe strong and significant differences between benchmark children and children at risk. Our study also only focused on a single year of schooling, whereas future research might explore associations between speech production skills and reading performance in grades one and beyond, and the specific effects that intervention, and type of intervention, may have on literacy and speech outcomes. The weak to moderate effects, while statistically significant, also suggest the need for replication. As we mentioned previously, our use of the DIBELS limited our ability to see the relation between specific letters and articulation of the phoneme they represent. In future work we will use an exhaustive test of letter knowledge to permit a more comprehensive analysis. Also, our measure of vocabulary was an expressive measure and as such involved some of the same skills as our test of speech production. Expressive vocabulary was one of the stronger correlates in our study and in the literature in general. Future work that tries to remove the confound of vocabulary might do well to include receptive vocabulary as another measure that would not share the demand on articulation. 
In conclusion, the present study provides evidence that speech production errors in children entering kindergarten, even if developmentally appropriate, may possibly be early markers of later difficulty learning to reading. Mastery of fricatives may be especially important for children learning the letters of the English alphabet, but the presence of fricatives in the letter names is not the sole reason why children prone to speech production errors are also prone to reading difficulties. Due to the entanglement of speech production skills, vocabulary, and memory with the developmental of early reading skills, children entering kindergarten with weak early reading skills may benefit from teaching practices and intervention programs that strengthen speech, expressive vocabulary, and memory as well as phonemic awareness and letter knowledge.

Acknowledgments The authors would like to thank the parents, children, teachers and school administrators who made this research possible. We also gratefully acknowledge the assistance of the following Loyola Marymount University students with data collection, transcription, scoring, data entry, and reliability assessments: Brent Cannons, Karla Dhungana, Vanessa Loaiza-Kois, and Rachelle Reeder.

Open Access This article is distributed under the terms of the Creative Commons Attribution Noncommercial License which permits any noncommercial use, distribution, and reproduction in any medium, provided the original author(s) and source are credited.

\section{Appendix 1}

See Table 6.

Table 6 Reading-related scores (means and standard error) for the eligible children (according to DIBELS) who received intervention and did not receive intervention at the beginning and end of the year

Eligible (DIBELS) for intervention

\begin{tabular}{ll}
\hline Received intervention & No intervention \\
$n=46$ & $n=25$ \\
\hline
\end{tabular}

\section{Beginning of the year}

DIBELS LNF

$$
\begin{gathered}
5.30(.92)^{* * *} \\
3.38(.45)^{* *} \\
.35(.15)^{*} \\
0(0)
\end{gathered}
$$

$$
0(0)
$$

End of the year

DIBELS LNF

$$
41.76 \text { (1.74) }
$$

\section{DIBELS PSF}

DIBELS NWF

DIBELS WRC

$4.70(.80)$

Woodcock-Johnson words

$3.67(.52)$
$5.72(.77)$

4.08 (1.08)

Children in intervention and no-intervention groups were significantly different on this measure

$* p<.05 ; * * p<.01 ; * * * p<.001$ 


\section{Appendix 2}

See Table 7.

Table 7 Reading-related scores and speech errors for the children who received the intervention and did not receive the intervention at the beginning and end of the year

\begin{tabular}{|c|c|c|}
\hline & \multicolumn{2}{|c|}{ Eligible (DIBELS) for intervention } \\
\hline & $\begin{array}{l}\text { Received intervention } \\
n=46\end{array}$ & $\begin{array}{l}\text { No intervention } \\
n=25\end{array}$ \\
\hline \multicolumn{3}{|l|}{ Beginning of the year } \\
\hline Digits-forward & $4.26(.31)^{* * *}$ & $5.05(.29)$ \\
\hline Digits-back & $.65(.15)^{* * *}$ & $1.67(.34)$ \\
\hline Expressive vocabulary & $46.98(1.44)^{* *}$ & $56.42(2.24)$ \\
\hline \multicolumn{3}{|l|}{ Speech errors } \\
\hline \multicolumn{3}{|l|}{ Age of acquisition errors } \\
\hline Early-8 & $28(.08)$ & $.16(.09)$ \\
\hline Middle-8 & $1.40(.20)^{* *}$ & $1.08(.27)$ \\
\hline Late- 8 & $4.91(.48)^{*}$ & $2.60(.54)$ \\
\hline \multicolumn{3}{|l|}{ Syllable position errors } \\
\hline Prevocalic & $10.64(1.7)$ & $6.43(1.42)$ \\
\hline Intervocalic & $11.17(1.11)$ & $6.43(1.34)$ \\
\hline Postvocalic & $6.89(.80)$ & $3.97(.98)$ \\
\hline \multicolumn{3}{|c|}{ Manner of production errors } \\
\hline Nasals & $2.39(.73)$ & $2.50(1.02)$ \\
\hline Stops & $1.54(.60)$ & $.89(.42)$ \\
\hline Fricatives & $19.97(1.92)^{* *}$ & $11.23(1.99)$ \\
\hline Affricates & $5.32(1.76)$ & $3.33(2.72)$ \\
\hline Liquids & $8.87(2.20)$ & $5.33(2.49)$ \\
\hline Glides & $2.70(1.14)$ & $0(0)$ \\
\hline Clusters & $13.39(2.68)$ & $9.41(3.26)$ \\
\hline \multicolumn{3}{|l|}{ Error type } \\
\hline Substitutions & $8.62(.93)^{* *}$ & $4.68(.93)$ \\
\hline Omissions & $.36(.10)$ & $.20(.08)$ \\
\hline Additions & $.13(.05)$ & $.16(.07)$ \\
\hline Cluster simplifications & $.28(.13)$ & $.48(.37)$ \\
\hline \multicolumn{3}{|l|}{ End of the year } \\
\hline Digits-forward & $5.33(.22)$ & $5.60(.51)$ \\
\hline Digits-back & $1.80(.22)^{* *}$ & $2.36(.28)$ \\
\hline Expressive vocabulary & $56.13(2.20)^{* *}$ & $63.40(2.41)$ \\
\hline \multicolumn{3}{|l|}{ Speech errors } \\
\hline \multicolumn{3}{|l|}{ Age of acquisition errors } \\
\hline Early-8 & $.18(.06)$ & $0(0)$ \\
\hline Middle-8 & $1.0(.18)$ & $.90(.35)$ \\
\hline
\end{tabular}


Table 7 continued

\begin{tabular}{|c|c|c|}
\hline & \multicolumn{2}{|c|}{ Eligible (DIBELS) for intervention } \\
\hline & $\begin{array}{l}\text { Received intervention } \\
n=46\end{array}$ & $\begin{array}{l}\text { No intervention } \\
n=25\end{array}$ \\
\hline Late-8 & $4.02(.51)$ & $2.90(.50)$ \\
\hline \multicolumn{3}{|l|}{ Syllable position errors } \\
\hline Prevocalic & $7.77(.88)$ & $4.32(1.02)$ \\
\hline Intervocalic & $9.67(1.05)$ & $9.29(1.40)$ \\
\hline Postvocalic & $8.19(.92)$ & $5.51(1.38)$ \\
\hline \multicolumn{3}{|c|}{ Manner of production errors } \\
\hline Nasals & $2.22(.82)$ & $1.79(.98)$ \\
\hline Stops & $.25(.17)$ & $0(0)$ \\
\hline Fricatives & $18.41(1.98)$ & $12.95(2.08)$ \\
\hline Affricates & $7.41(2.28)$ & $8.73(5.09)$ \\
\hline Liquids & $6.67(1.87)$ & $7.14(3.91)$ \\
\hline Glides & $5.56(2.37)$ & $0(0)$ \\
\hline Clusters & $10.85(2.20)$ & $8.68(2.55)$ \\
\hline \multicolumn{3}{|l|}{ Error type } \\
\hline Substitutions & $6.43(.72)$ & $4.95(.85)$ \\
\hline Omissions & $.16(.06)$ & $.19(.09)$ \\
\hline Additions & $.20(.07)$ & $.14(.08)$ \\
\hline Cluster simplifications & $.22(.10)$ & $.24(.24)$ \\
\hline
\end{tabular}

Children in intervention and no-intervention groups were significantly different on this measure

$* p<.05 ; * * p<.01 ; * * * p<.001$

\section{Appendix 3}

See Table 8.

Table 8 Year-end DIBELS and Woodcock-Johnson reading scores for eligible children who received the intervention compared to children who did not receive the intervention, adjusted for memory and vocabulary differences in the groups at the beginning of kindergarten

Eligible (DIBELS) for intervention

\begin{tabular}{lll}
\hline Intervention & No intervention & Effect size \\
$n=46$ & $n=25$ & Cohen's $d$
\end{tabular}

DIBELS

Letter naming fluency

Phoneme segmenting fluency

Nonword fluency

Words read correctly

Woodcock-Johnson

Words

$44.94(1.95)^{*}$
$34.76(2.27)^{* * *}$
$31.98(2.37)^{*}$
$5.20(.82)^{*}$
$6.74(.62)$

$36.51(2.39)$

.67

$22.03(2.78) \quad .92$

$23.21(2.90)$

.57

$1.88(1.00)$

.63

$4.96(.76)$

.44 
Table 8 continued

\begin{tabular}{lccc}
\hline & \multicolumn{2}{l}{ Eligible (DIBELS) for intervention } & \\
\cline { 2 - 4 } & $\begin{array}{l}\text { Intervention } \\
n=46\end{array}$ & $\begin{array}{l}\text { No intervention } \\
n=25\end{array}$ & $\begin{array}{l}\text { Effect size } \\
\text { Cohen's } d\end{array}$ \\
\hline Nonwords & $4.27(.62)$ & $2.77(.76)$ & .37 \\
Speech measure improvements (selected) & $-1.27(.48)^{*}$ & $.67(.67)$ & .59 \\
Late-8 errors & $-3.41(1.91)$ & $3.17(2.7)$ & .50 \\
Fricative errors & $-1.98(1.19)^{*}$ & $3.07(1.66)$ & .62 \\
Intervocalic errors &
\end{tabular}

Children in intervention and no-intervention groups were significantly different on this measure

$* p<.05 ; * * p<.01 ; * * * p<.001$

\section{References}

Al Otaiba, S., \& Torgesen, J. (2007). Effects from intensive standardized kindergarten and first-grade interventions for the prevention of reading difficulty. In S. R. Jimerson, M. K. Burns, \& A. M. Van Der Heyden (Eds.), Handbook of response to intervention. The science and practice of assessment and intervention (pp. 212-222). New York, NY: Springer.

Anthony, J. L., \& Francis, D. J. (2005). Development of phonological awareness. Current Directions in Psychological Science, 14(5), 255-259.

Baddeley, A. D. (1986). Human memory: Theory and practice. Hove, England: Erlbaum.

Baddeley, A. D. (2003). Working memory and language: An overview. Journal of Communication Disorders, 36, 189-208.

Berninger, V. W., Abbott, R. D., Thomson, J., Wagner, R., Swanson, H. L., Wijsman, E. M., et al. (2006). Modeling phonological core deficits within a working memory achitecture in children and adults with developmental dyslexia. Scientific Studies of Reading, 10(2), 165-198.

Berninger, V. W., Abbott, R. D., Vermeulen, K., Ogler, S., Brooksher, R., Zook, D., et al. (2002). Comparison of faster and slower responders to early intervention in reading: Differentiating features of their language profiles. Learning Disability Quarterly, 25, 59-76.

Bishop, D. V. M., \& Adams, C. (1990). A prospective study of the relationship between specific language impairment, phonological disorders and reading retardation. Journal of Child Psychology and Psychiatry and Applied Disciplines, 31(7), 1027-1050.

Carroll, J. M., Snowling, M., Hulme, C., \& Stevenson, J. (2003). The development of phonological awareness in preschool children. Developmental Psychology, 39(5), 913-923.

Catts, H. (1986). Speech production/phonological deficits in reading-disordered children. Journal of Learning Disabilities, 19, 504-508.

Catts, H. (1993). The relationship between speech-language impairments and reading disabilities. Journal of Speech and Hearing Research, 36, 948-958.

Catts, H., Fey, M. E., Zhang, X., \& Tomblin, J. B. (2001). Estimating the risk of future reading difficulties in kindergarten children: A research-based model and its clinical implementation. Language, Speech, and Hearing Services in Schools, 32(1), 38-50.

Compton, D. (2006). How should 'unresponsiveness' to secondary intervention be operationalized? It is all about the nudge. Journal of Learning Disabilities, 39(2), 170-173.

Dahlin, E., Neely, A. S., Larsson, H., Backman, L., \& Nyberg, L. (2008). Transfer of learning after updating training mediated by the striatum. Science, 320, 1510-1512.

Diamond, A. (2005). Attention-deficit disorder (attention-deficit/hyperactivity disorder without hyperactivity): A neurobiologically and behaviorally distinct disorder from attention-deficit/hyperactivity disorder (with hyperactivity). Development and Psychopathology, 17, 807-825.

Engel, P. M. J., Sanos, F. H., \& Gathercole, S. E. (2008). Are working memory measures free of socio-economic influence? Journal of Speech, Language, and Hearing Research, 51, 1580-1587. 
Fowler, A. E. (1991). How early phonological development might set the stage for phonological awareness. In S. Brady \& D. Shankweiler (Eds.), Phonological processes in literacy: A tribute to Isabelle Y. Liberman (pp. 97-117). Hillsdale, NJ: Lawrence Erlbaum Associates.

Fowler, A. E., \& Swainson, B. (2004). Relationships of naming skills to reading, memory, and receptive vocabulary: evidence for imprecise phonological representations of words by poor readers. Annals of Dyslexia, 54(2), 247-280.

Foy, J. G. (2009). Effectiveness of the Bookworm Project: A university-school partnership providing lowcost, research-based early reading intervention for at-risk kindergarteners. Early Childhood Services, 3(4), 281-300.

Foy, J. G., \& Mann, V. A. (2006). Changes in letter sound knowledge are associated with development of phonological awareness in preschool children. Journal of Research in Reading, 29(2), 143-161.

Gathercole, S. E., Alloway, T. P., Willis, C. S., \& Adams, A. M. (2006). Working memory in children with reading disabilities. Journal of Experimental Child Psychology, 93, 265-281.

Gathercole, S. E., \& Baddeley, A. D. (1993). Phonological working memory: A critical building block for reading development and vocabulary acquisition? European Journal of Psychology of Education, $8(3), 259-273$.

Gathercole, S. E., \& Pickering, S. J. (2001). Working memory deficits in children with special educational needs. British Journal of Special Education, 28, 89-97.

Gathercole, S. E., Willis, C. S., Emslie, H., \& Baddeley, A. D. (1992). Phonological memory and vocabulary development during the early school years: A longitudinal study. Developmental Psychology, 28(5), 887-898.

Gilchrist, A. L., Cowan, N., \& Naveh-Benjamin, M. (2009). Investigating the childhood development of working memory using sentences: New evidence for the growth of chunk capacity. Journal of Experimental Child Psychology, 104, 252-265.

Goldman, R., \& Fristoe, M. (2000). Goldman-fristoe test of articulation-2. Circle Pines, MN: American Guidance Service.

Goswami, U., \& Bryant, P. (1990). Phonological skills and learning to read. Hove, UK: Erlbaum.

Henry, L. A. (2001). How does the severity of a learning disability affect working memory performance? Memory, 9, 233-247.

Hindman, A. H., Connor, C. M., Jewkes, A. M., \& Morrison, F. J. (2008). The effects of shared book reading: Multiple factors and associations with preschool literacy outcomes. Early Childhood Research Quarterly, 23, 330-350.

Hindson, B., Byrne, B., Fielding-Barnsley, R., Newman, C., \& Hine, D. W. (2005). Assessment and early instruction of preschool children at risk for reading disability. Journal of Educational Psychology, 97(4), 687-704.

Kaminski, R., \& Good, R. H. I. (1996). Toward a technology for assessing basic early literacy skills. School Psychology Review, 25(2), 215-227.

Kent, R. D., \& Read, C. (1992). The acoustic analysis of speech. San Diego, CA: Singular Publishing.

Keren-Portnoy, T., Vihman, M. M., DePaolis, R. A., Whitaker, C. J., \& Williams, N. M. (2010). The role of vocal practice in constructing phonological working memory. Journal of Speech, Language, and Hearing Research, 53, 1280-1293.

Klingberg, T., Fernell, E., Olesen, P., Johnson, M., Gustafsson, P., Dahlstrom, K., et al. (2005). Computerized training of working memory in children with ADHD-A randomized controlled trial. Journal of the Academy of Adolescent and Child Psychiatry, 44(2), 177-186.

Leather, V. J., \& Henry, L. A. (1994). Working memory spans and phonological tasks as predictors of early reading ability. Journal of Experimental Child Psychology, 58, 88-111.

Leitao, S., \& Fletcher, J. (2004). Literacy outcomes for students with speech impairment: Long-term follow-up. International Journal Language Communication Disorders, 39, 245-256.

Mann, V. A., \& Foy, J. G. (2003). Speech development, phonological awareness, and letter knowledge in preschool children. Annals of Dyslexia, 53, 149-173.

Mann, V. A., \& Foy, J. G. (2007). Speech production patterns and phonological awareness in preschool children. Annals of Dyslexia, 57(1), 51-74.

Mathes, P. G., Denton, C. A., Fletcher, J. M., Anthony, J. L., Francis, D. J., \& Schatschneider, C. (2005). The effects of theoretically different instruction and student characteristics on the skills of struggling readers. Reading Research Quarterly, 40(2), 148-182.

Metsala, J. L. (1997). Spoken word recognition in reading disabled children. Journal of Educational Psychology, 89, 159-169. 
Mody, M. (2003). Phonological basis in reading disability: A review and analysis of the evidence. Reading and Writing: An Interdisciplinary Journal, 16(1-2), 21-39.

Nathan, L., Stackhouse, J., Goulandris, N., \& Snowling, M. (2004a). Educational consequences of developmental speech disorder: Key stage I national curriculum assessment results in English and mathematics. British Journal of Educational Psychology, 74, 173-186.

Nathan, L., Stackhouse, J., Goulandris, N., \& Snowling, M. J. (2004b). The development of early literacy skills among children with speech difficulties: a test of the "critical age hypothesis". Journal of Speech, Language, and Hearing Research, 47(2), 377-391.

Norusis, M. J. (2000). Guide to data analysis. Upper Saddle River, NJ: Prentice Hall.

Porter, J. H., \& Hodson, B. W. (2001). Collaborating to obtain phonological acquisition data for local schools. Language, Speech, and Hearing Services in Schools, 32(3), 165-171.

Preston, J., \& Edwards, M. L. (2010). Phonological awareness and types of sound errors in preschoolers with speech sound disorders. Journal of Speech, Language and Hearing Research, 53, 44-60.

Rathvon, N. (2004). Early reading assessment: A practitioner's handbook. New York, NY: Guilford.

Rvachew, S., \& Grawburg, M. (2006). Correlates of phonological awareness in preschoolers with speech sound disorders. Journal of Speech, Language and Hearing Research, 49, 74-87.

Savage, R., Cornish, K., Manly, T., \& Hollis, C. (2006). Cognitive processes in children's reading and attention: The role of working memory, divided attention, and response inhibition. British Journal of Psychology, 97, 365-385.

Savage, R., Lavers, N., \& Pillay, V. (2007). Working memory and reading difficulties: What we know and what we don't know about the relationship. Educational Psychology Review, 19, 185-221.

Serniclaes, W. I., Van Heghe, S., Mousty, P., Carre, R., \& Sprenger-Charolles, L. (2004). Allophonic mode of speech perception in dyslexia. Journal of Experimental Child Psychology, 87, 336-361.

Shriberg, L. D. (1993). Four new speech and prosody-voice measures for genetics research and other studies in developmental phonological disorders. Journal of Speech and Hearing Research, 36, $105-140$.

Shriberg, L. D., \& Kwiatkowski, J. (1994). Developmental phonological disorders I: A procedure for assessing severity of involvement. Journal of Speech and Hearing Disorders, 37, 1100-1126.

Shriberg, L. D., Kwiatkowski, J., \& Gruber, F. A. (1994). Developmental phonological disorders II: Short-term speech-sound normalization. Journal of Speech and Hearing Research, 37, 1127-1150.

Shriberg, L. D., Tomblin, J. B., \& McSweeny, J. L. (1999). Prevalence of speech delay in 6-year-old children and comorbidity with language impairment. Journal of Speech, Language and Hearing Research, 42(6), 1461-1481.

Smit, A. B. (1993a). Phonologic error distributions in the Iowa-Nebraska articulation norms project: Consonant singletons. Jounrnal of Speech, Language, and Hearing Research, 36, 533-547.

Smit, A. B. (1993b). Phonological error distributions in the Iowa-Nebraska articulation norms project: Word initial consonant clusters. Journal of Speech and Hearing Research, 36, 931-947.

Smith, S. L. (2009). Early phonological and lexical markers of reading disabilities. Reading and Writing: An Interdisciplinary Journal, 22(1), 25-40.

Snowling, M. (1981). Phonemic deficits in developmental dyslexia. Psychological Research, 43, 219-234.

Snowling, M., Goulandris, N., Bowlby, M., \& Howell, P. (1986). Segmentation and speech perception in relation to reading skill: A developmental analysis. Journal of Experimental Child Psychology, 41, 489-507.

Stage, S. A., \& Wagner, R. K. (1992). Developmental of young children's phonological and orthographic knowledge as revealed by their spellings. Developmental Psychology, 28(2), 287-296.

Swan, D., \& Goswami, U. (1997). Phonological awareness deficits in developmental dyslexia and the phonological representations hypothesis. Journal of Experimental Child Psychology, 66, 18-41.

Swanson, L., \& Jerman, O. (2006). The influence of working memory on reading growth in subtypes of children with reading disability. Journal of Experimental Child Psychology, 96(4), 249-283.

Tabachnick, B. G., \& Fidell, L. S. (2001). Using multivariate statistics (4th ed.). New York, NY: Harper Collins.

Tallal, P., \& Piercy, M. (1974). Developmental aphasia: Rate of auditory processing and selective impairment of consonant perception. Neuropsychologia, 12(1), 83-93.

Treiman, R. (1984). On the status of final consonants in English syllables. Journal of Verbal Learning and Verbal Behavior, 23(3), 343-356.

Treiman, R., Berch, D., \& Weatherston, S. (1993). Children's use of phoneme-grapheme correspondences in spelling: Roles of position and stress. Journal of Educational Psychology, 85(3), 466-477. 
Treiman, R., Broderick, V., Tincoff, R., \& Rodriguez, K. (1998). Children's phonological awareness: Confusions between phonemes that differ only in voicing. Journal of Experimental Child Psychology, 68(1), 3-21.

Treiman, R., Sotak, L., \& Bowman, M. (2001). The role of letter names and letter sounds in connecting print and speech. Memory and Cognition, 29, 860-873.

University of Oregon. (n.d.). In DIBELS benchmark goals: Kindergarten. Retrieved from https://dibels.uoregon.edu/benchmark.php\#3kindergarten.

Van Leeuwen, T., Been, P., Van Herten, M., Zwarts, F., Maassen, B., \& Van Der Leij, A. (2007). Cortical categorization failure in 2-month-old infants at risk for dyslexia. NeuroReport, 18(9), 857-861.

Vellutino, F. R., Scanlon, D. M., Small, S., \& Fanuele, D. P. (2006). Response to intervention as a vehicle for distinguishing children with and without reading disabilities. Journal of Learning Disabilities, 39 (2), 157-169.

Walley, A. C. (1993). The role of vocabulary development in children's spoken word recognition and segmentation ability. Developmental Review, 13, 286-350.

Walley, A. C., Metsala, J. L., \& Garlock, V. M. (2003). Spoken vocabulary growth: Its role in the development of phoneme awareness and early reading ability. Reading and Writing: An Interdisciplinary Journal, 16(1-2), 5-20.

Wechsler, D. (1992). Wechsler intelligence scale for children. London, England: Psychological Corporation.

Werker, J. F., \& Tees, R. C. (1987). Speech perception in severely disabled and average reading children. Canadian Journal of Psychology, 41, 48-61.

Williams, L. A. (2001). Phonology assessment of child speech. In D. M. Ruscello (Ed.), Tests and measurement in speech language pathology (pp. 31-76). Woburn, MA: Butterworth-Heinemann.

Williams, K. T. (2006). The expressive vocabulary test 2 (2nd ed.). Circle Pines, MN: American Guidance Service.

Woodcock, R. M. (1987). Woodcock reading mastery-Revised, form H. Circle Pines, MN: American Guidance Service. 